DOI: 10.17707/AgricultForest.61.2.05

\author{
Babak DARVISHI, Hamid MOHAMMADI, \\ Javid KARDAN, Eshagh Ali BAYATI, AmirReza SADEGHI ${ }^{1}$
}

\title{
THE EFFECT OF PLANTLETS DENSITY AND GROWTH MEDIA COMPOSITION ON POTATO MINI-TUBER PRODUCTION IN HYDROPONIC SAND CULTURE
}

\begin{abstract}
SUMMARY
Hydroponic Sand Culture (HSC) is a relatively low cost method for potato minituber production. Intensive production under HSC requires applying appropriate growth media composition and plantlet density. An experiment was conducted under HSC in a controlled greenhouse to evaluate growth media composition and plantlet density effect on potato micropropagated plantlets growth, tuberization and concentration of petiole phosphorus and leaf nitrogen. A factorial experiment based on randomized complete block design with 3 replications was used. Studied factors included different 3 growth media composition (fine, medium and coarse) and 2 plantlet density (100 and 150 plantletm-2). Results showed that establishment and biological yield of potato crops grown in coarse composition was significantly higher than the other compositions. Plantlet density had not significant effect on the tuber number per plant and seed sized tuber number per plot. Tuber DW and tuber number per plant was significantly increased in coarse composition of growth media. Fine composition reduced availability of $\mathrm{P}$ but not of $\mathrm{N}$, resulting in higher petiole $\mathrm{P}$ concentration of crops planted in coarse composition. Coarse composition of growth media was the best composition for potato minituber production in hydroponic sand culture.
\end{abstract}

Keywords: Nitrogen, Phosphorus, Specific gravity, Tuberization.

\section{INTRODUCTION}

Hydroponic production of potato (Solanum tuberosum L.) mini-tuber is a technique by which a large number of tubers are multiplied. Adding substrate to the system is a tool to enhance chemical and physical inertia. As a consequence, labour and energy are saved (Rolot and Seutin, 1999). A relatively low cost method for potato mini-tuber production was adopted by sand (size ranging from 0 to $6 \mathrm{~mm}$ ) as a growth media which provides an inert nature media with more pore volume (more oxygen transport), stable structure, less water retention and large volume of accessible water to the plants (Dole and Wilkins, 1999). One of

\footnotetext{
${ }^{1}$ Babak Darvishi, (Corresponding author: bdarvishi_84@yahoo.com), Seed and Plant Certification and Registration Research Institute (SPCRI), Iran , Hamid Mohammadi, Javid Kardan, Amir Reza Sadeghi, Faculty of agriculture, Azarbaijan Shahid Madani University, Iran, Eshagh Ali Bayati, Kaboodarahang Pnu University, Iran.

Notes: The authors declare that they have no conflicts of interest. Authorship Form signed online.
} 
the main characteristics of sand as growth media is suitable air-filled porosity for efficient oxygen diffusion and water maintaining. The mechanical resistance of sand may also affect stolon and tuber development. Insufficient resistance can result in vigorous stolon growth (Cary, 1986) or secondary stolons and many small tubers (Vreugdenhil and Struik, 1989).

The differences in planting material may result in different multiplication rate of potato micropropagated plantlets. Increased water capacity of growth media adversely affect on oxygen diffusion in media (Cho et al., 2006). Aeration is one of critical factors influencing root and plant growth. Wever et al. (2001) found that air-filled porosity has an important role in oxygen diffusion in rooting medium. They clarified if air-filled porosity reduced to less than $30 \%(\mathrm{v} / \mathrm{v})$, the oxygen concentration would drop to less than $20 \%$. If rooting medium suffers from oxygen deficiency, plant will be injured severely or dead (Cherif et al., 1997). Especially in potato plant, due to its sparse and shallow root system (Fulai et al., 2006), oxygen deficiency plays more remarkable role. Metabolic processes like ion absorption can be prohibited by root oxygen deficiency (Caron and Nkongolo, 2004).

Phosphorus is an essential plant nutrient that is especially important in promoting early crop growth (Jenkins and Ali, 1999). The increase in vegetative weight of potato plant as a result of higher plant $\mathrm{P}$ concentration is expected because of the importance of $\mathrm{P}$ in plant growth. Phosphorus plays a major role in cell division, cell enlargement, energy storage and energy release (Thorup, 1984). Further, $\mathrm{P}$ can increase plant vegetative weight by increasing the leaf area produced per plant (Watson and Wilson, 1956). Phosphorus nutrition can play an important role in regulating potato tuber set. Rosen and Bierman (2008) reported that petiole $\mathrm{P}$ was positively correlated with the number of tubers per plant. Westermann and Kleinkopf (1985) found that $\mathrm{P}$ concentration in petiole less than $1000 \mathrm{\mu gg}^{-1}$ was inadequate for potato tuber growth.

Intensive production under HSC requires applying appropriate growth media and plantlet density. The objectives of this study were to: 1 . determine the effects of different growth media compositions on the tuberization and yield of micropropagated potato plantlets and 2 . Select the plant density that would maximize micropropagated potato plantlet tuber production grown in hydroponic sand culture.

\section{Plantlet establishment}

\section{MATERIAL AND METHODS}

To raise plantlets through micropropagation, stem cuttings as single nodes were taken from sterilized plant stems using 'Sante' potato cultivar (the most widely grown potato cultivar in Iran). Then plantlets were transferred into a sterile MS culture media (Murashige and Skoog, 1962) and were exposed to 16 hour photoperiod $\left[60 \mu \mathrm{molm}^{-2} \mathrm{~s}^{-1}\right.$ Photosynthetic Photon Flux Density (PPFD) provided by cool white and red fluorescent lamps] and $22 \pm 1^{\circ} \mathrm{C}$ temperature regime for 3 weeks. After 21 days, the single stem plantlets were subcultured and 
micropropagated on the same medium to produce sufficient numbers of plantlets for the experimental trials.

\section{Bed experiments}

The experimental set up was an opened HSC system under greenhouse conditions in Giah Baft Gharb Co. Hamedan, Iran. Three cement frame of $6 \times 1.2$ $\times 0.3 \mathrm{~m}$ was used to contain the growth media. Sand $(1-5 \mathrm{~cm})$ was used in the bottom of the bed, and then it was covered with a perforated polyethylene sheet (holes in every $15 \mathrm{~cm}$ ). The growth media was placed in this frame and hilled surface of the polyethylene sheet. On Februery 20th, 2014, the uniform 4-6 cm height plantlets were transplanted into $1.2 \times 1 \mathrm{~m}$ plant beds filled with sand with $10 \mathrm{~cm}$ depth. Interplant spacing was $10 \times 10$ or $10 \times 15 \mathrm{~cm}$ with a total of 100 or 150 plantletm $^{-2}$, respectively. Transplanted plantlets were covered with clear plastic for the first 7 days from 4 PM to 10 AM to minimize transplanting shock, to avoid desiccation and low temperature stresses.

To investigate the effect of plantlet density and substrate composition on potato cultivar performance in terms of plant growth, tuberization and nitrogen and phosphorous accumulation, a factorial experiment based on randomized complete block design with 3 replications was used. The studied factors included growth media composition (1. 30\% of $0-3 \mathrm{~mm}$ and $70 \%$ of $3-6 \mathrm{~mm}, 2.50 \%$ of 0 $3 \mathrm{~mm}$ and $50 \%$ of $3-6 \mathrm{~mm}, 3.100 \%$ of $0-3 \mathrm{~mm}$ sand size) and plantlet density (100 and 150 plantletsm $^{-2}$ ).

\section{Nutrition}

Standard nutrient solution was prepared (Table 1) and Transferred plantlets were fertilized with nutrient solution when needed. Nutrient solution was contained in $200 \mathrm{~L}$ reservoirs outside the greenhouse in a dark chamber to avoid alga growth and applied to production system using black plastic tubes with an outflow of $1.5 \mathrm{~L}$ per min through a tube powered by a $0.5 \mathrm{hp}$ motor-pomp. The $\mathrm{pH}$ of nutrient solution was adjusted for 5.8-6 and electrical conductivity (EC) for $2 \mathrm{mScm}^{-1}$ according to Farran and Mingocastel (2006) recommendations. The EC of drainage solution was measured every week. To avoid salinity stress, whenever the $\mathrm{EC}$ of sand passed $3 \mathrm{mScm}^{-1}$, it was adjusted by adding well water (EC: $0.5 \mathrm{mScm}^{-1}$ ) (Novella et al., 2008).

Plant hilling was done by addition of more growth media, 30 and 50 DATP to depth of $20 \mathrm{~cm}$ and $30 \mathrm{~cm}$ respectively. The average ambient temperature was about $20^{\circ} \mathrm{C}$, with maximum and minimum of $15^{\circ} \mathrm{C}$ and $25^{\circ} \mathrm{C}$, respectively. The photoperiod was $14 \mathrm{~h}$ and natural light with Photosynthetically Active Radiation (PAR) of 300 to $650 \mu \mathrm{molm}^{-2} \mathrm{~s}^{-1}$ at the top of the plant canopy supplemented with alternating high pressure sodium lamps.

\section{Measurements}

Number and length of established plantlets were recorded at 20 DATP. Leaf gas exchange (net photosynthesis rate and rate of transpiration) and growth 
characteristics including leaf area, leaf DW and stem DW were measured at 50 DATP. Meanwhile 5 plants were selected randomly from each plot, labeled and their shoot was harvested, weighted and oven dried for $48 \mathrm{~h}$ at $75^{\circ} \mathrm{C}$. The tubers of labeled plants were harvested, oven dried for $48 \mathrm{~h}$ at $75^{\circ} \mathrm{C}$ and weighted individually. Harvest index was calculated as a ratio of average tuber DW divided by average plant biomass of each treatment, excluding root DW. Seven days after haulm killing, tubers and roots were carefully removed from the growth media. Tubers from each plot were rinsed free from soil; tuber numbers per plot and numbers of seed tubers (in seed size: 12-35 $\mathrm{mm}$ ) per plot were recorded. Specific gravity of tubers was measured according to Kleinkopf et al. (1987); in which tubers from each plot were weighted in air and in water, and applied to the following formula:

$$
\frac{\text { Weight in air }}{\text { Weight in air - Weight in water }}
$$

Leaf samples from each plot was dried at $60^{\circ} \mathrm{C}$, ground and passed through a 40mesh screen and analyzed for total nitrogen (macro-Kjeldahl method, AOAC, 1984) and phosphorous (Minocha et al., 1994).

\section{Statistical analysis}

The data were analyzed using the SAS statistical package and the mean comparisons were made following Duncan's multiple range test at $\mathrm{P}=0.05$ by MSTATC (version 2.10; Michigan State University East Lansing, MI, USA).

\section{Establishment}

\section{RESULTS AND DISCUSSION}

According to the ANOVA (Table 2), significant ( $\mathrm{P}<0.05)$ differences between growth media compositions with respect to the plantlets establishment was observed; plantlets establishment in coarse composition (30\% of 0-3 $\mathrm{mm}$ and $70 \%$ of 3-6 mm) was significantly higher than the medium $(50 \%$ of $0-3 \mathrm{~mm}$ and $50 \%$ of 3-6 mm) and fine (100\% of 0-3 mm) composition (Table 4). It seems fine composition of planting material resulted in reduced air-filled porosity of growth media which adversely affected micropropagated plantlets establishment. Although plantlets establishment significantly increased from 82.3 in lower plant density to 101.2 in higher plant density, plantlets survival was higher in lower plant density (Table 4).

\section{Plant growth characteristics}

There were no significant differences in plant stem length among growth media compositions. Higher planting density significantly increased plant stem length (Table 4). There was significant interaction between growth media composition and plant density with respect to the leaf area and leaf DW (Table $2)$; under the lower plant density (100 plantletm $^{-2}$ ) leaf area was significantly higher in fine and medium composition compared to the coarse composition of growth media, whereas under the higher plant density $\left(150\right.$ plantletm $\left.^{-2}\right)$ leaf area 
of potato crops planted in medium composition was significantly reduced (Figure 1). In both plant densities, the higher leaf DW was observed in coarse growth media composition (Figure 2).

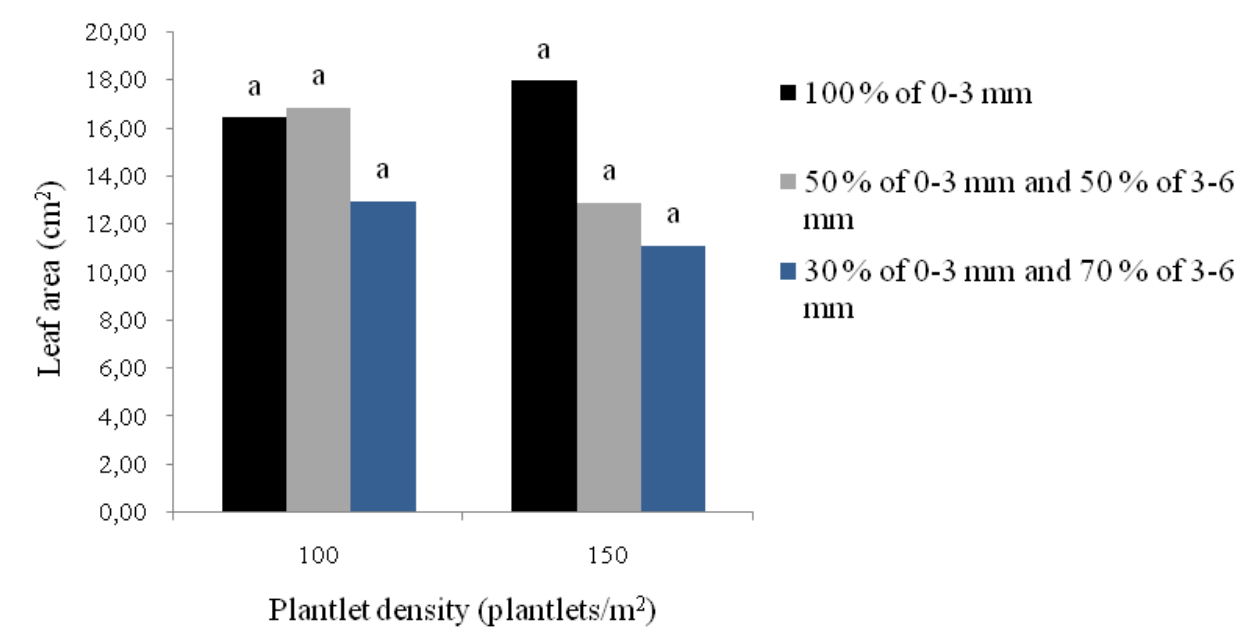

Figure 1. Influence of growth media composition and plantlet density interaction on leaf area of potato crops

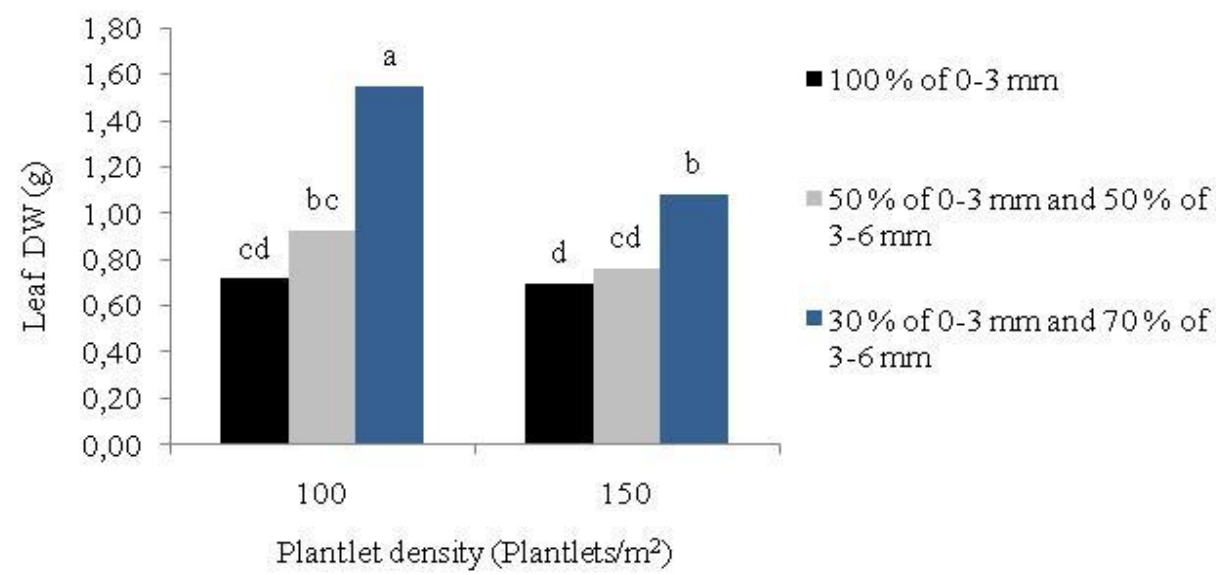

Figure 2. Influence of growth media composition and plantlet density interaction on leaf DW of potato crops

There was no significant difference among the three types of growth media composition and two densities of plant for the stem DW, net photosynthesis rate and rate of transpiration (Table 2).

Biological yield of potato crops was significantly affected by growth media composition and plant density (Table 3). The observed higher biological yield of coarse composition compared to the other fine compositions (Table 4) revealed that the increasing of fine materials in growth media negatively affected the potato plants growth and yield. Biological yield of potato plants was negatively influenced by plant density (Table 4 ). 

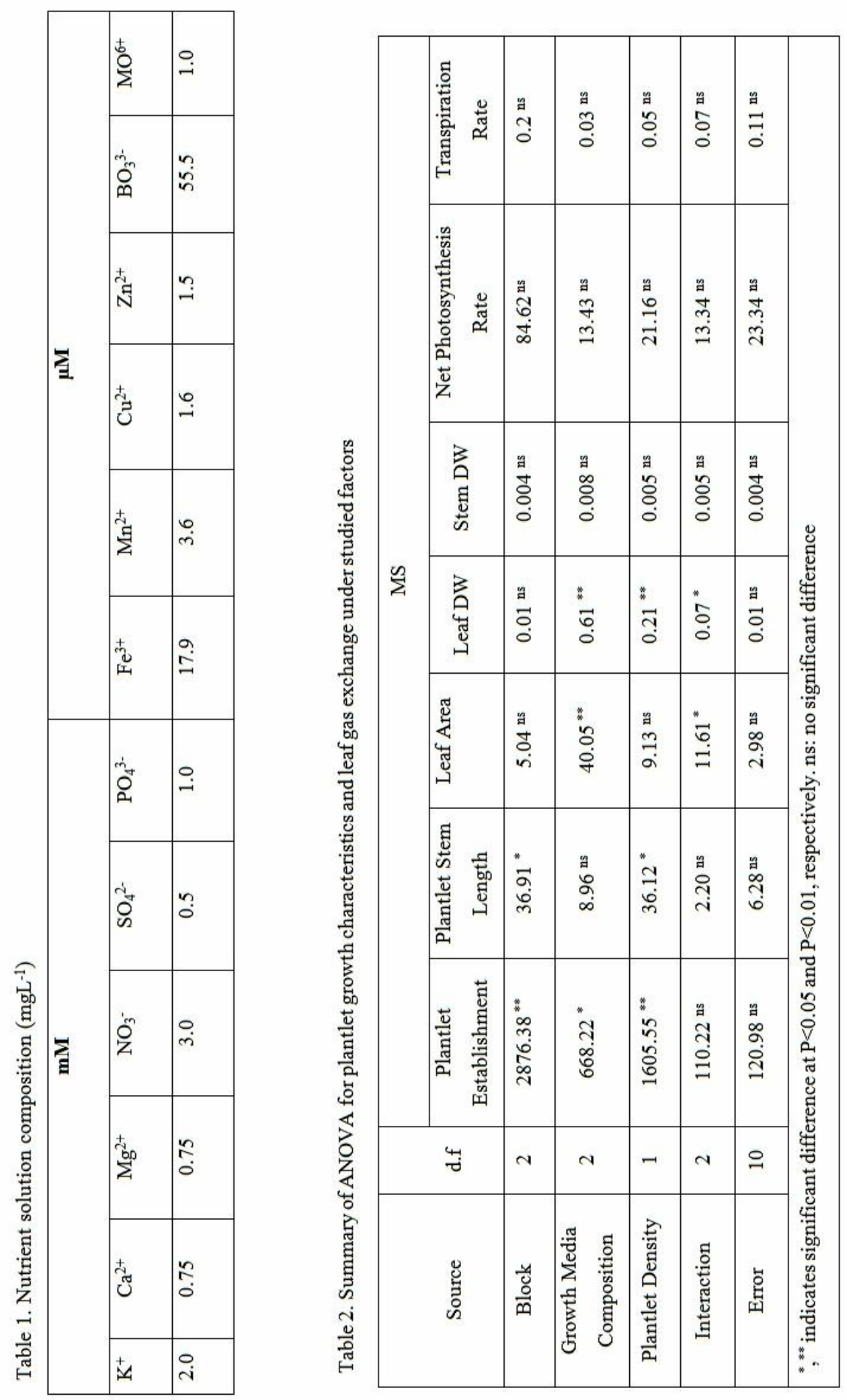


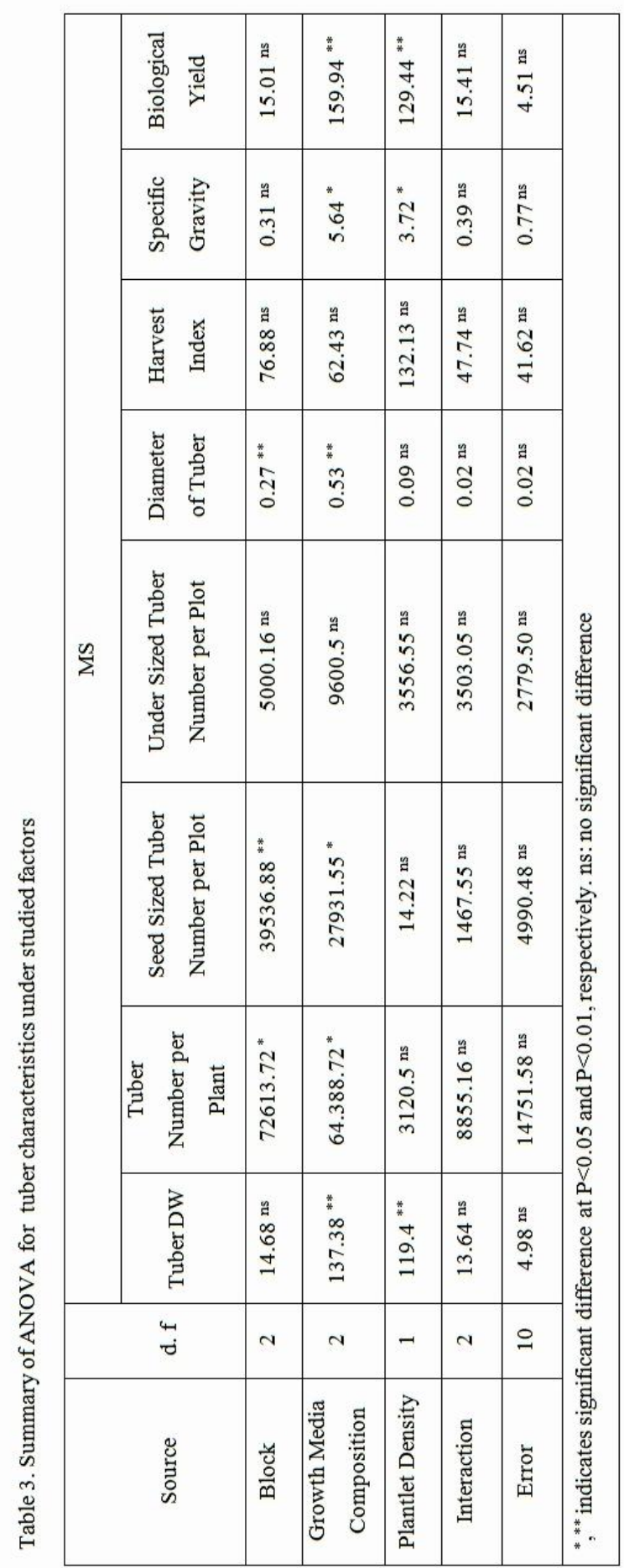




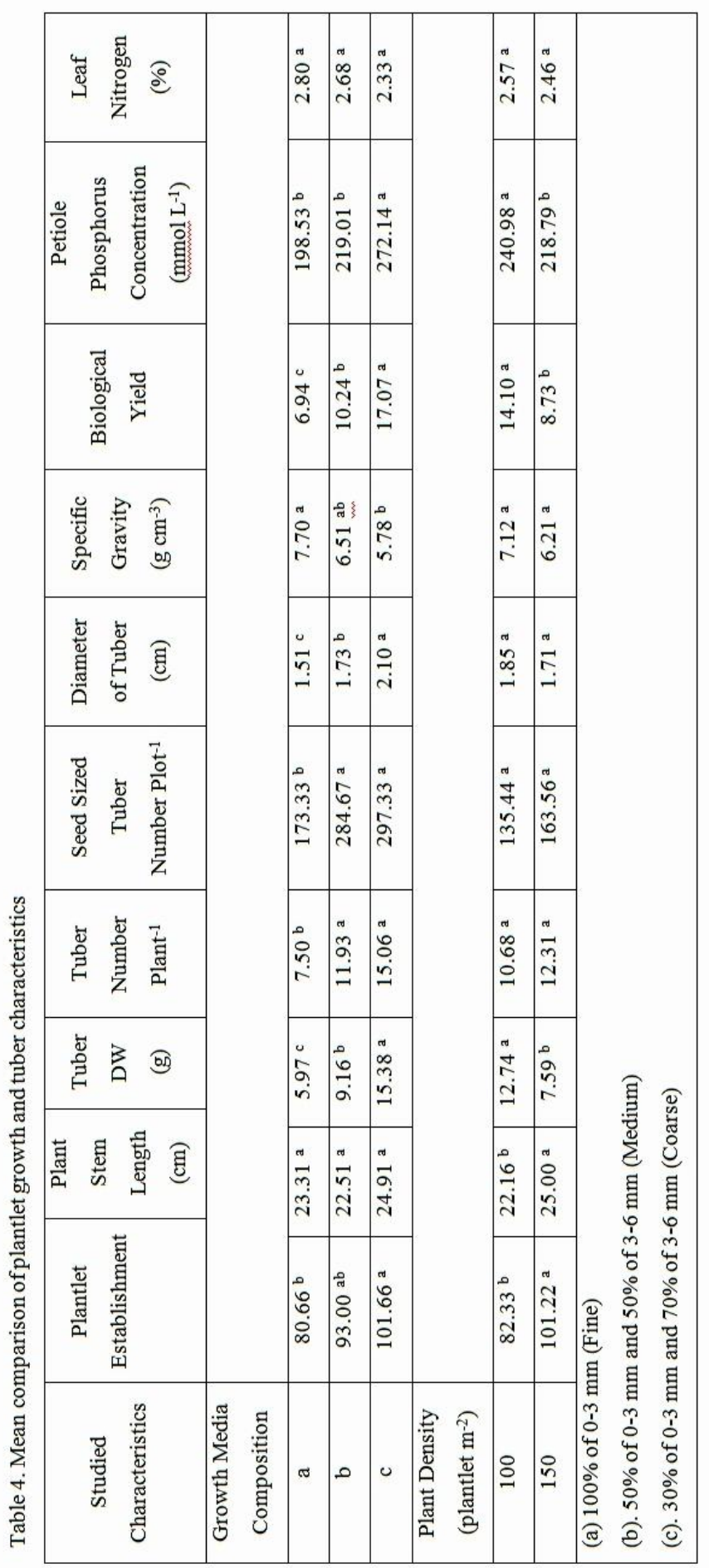




\section{Tuber characteristics at harvest}

Tuber DW per plant was significantly influenced by the growth media composition and plant density (Table 3). It is apparent that tuber DW significantly reduced with increasing fine material $(0-3 \mathrm{~mm})$ amount in growth media composition (Table 4). Average tuber DW per plant was $12.74 \mathrm{~g}$ in 100 plantlet $\mathrm{m}^{-2}$ as compared to $7.59 \mathrm{~g}$ for the 150 plantlet $\mathrm{m}^{-2}$. Growth media composition significantly affected the quantity of potato tubers harvested (Table $3)$. Fine composition of growth media significantly reduced tuber number per plant (Table 4). The highest seed sized $(12-35 \mathrm{~mm})$ tuber number per plot was observed in coarse and medium composition of growth media. Plant density had not significant effect on the tuber number per plant and seed sized tuber number per plot (Table 4). The largest tubers produced in coarse composition of growth media; the growth media composition was finer, diameter of tuber was significantly reduced (Table 4). It appears from the tuber number and tuber weight data that the reduced porosity caused by the fine composition of growth media resulted in a reduction of tuber growth and number. Specific gravity of produced tubers was significantly influenced by growth media composition (Table 2). The highest specific gravity of tubers was observed in fine growth media composition (Table 4). Diameter and specific gravity of produced tubers was not significantly affected by plant density.

\section{$P$ and $N$ concentration}

Two elements that were measured in the research included phosphorus and nitrogen. There was no effect of growth media composition and plant density on leaf nitrogen percent (Table 4). Petiole phosphorus concentration of potato crops planted in coarse composition of growth media was significantly higher than the other studied compositions. It seems fine composition of growth media reduced availability of $\mathrm{P}$ but not of $\mathrm{N}$, resulting in different foliar $\mathrm{P}$ concentration.

Increased plant density significantly reduced petiole phosphorus concentration (Table 4). Therefore, our findings showed that the promoting effect of growth media composition on seed sized tuber number per plot was demonstrated by the increasing petiole phosphorus concentration (Table 4). It is postulated that higher phosphorus concentration induced tuberization, increased seed sized tuber number per plot and enhanced diameter of tubers. Balemi (2009) reported that low P supply reduced shoot DW yield, total leaf area per plant and plant height of potato crops. However, low $\mathrm{P}$ supply did not affect net photosynthetic rate per unit leaf area. Phosphorus deficiency leads to a general reduction of most metabolic processes including cell division, cell expansion, respiration and photosynthesis (Terry and Ulrich, 1973). Under hydroponic minituber production, root ability of potato plants to recover phosphorus is low and therefore phosphorus deficiency could be a limiting factor (Pursglove and Sanders, 1981). It has also been reported that increased phosphorus concentration in a nutrient solution increased tuber numbers and reduced the ratio of big tubers (>65 mm) (Jenkins and Ali, 2000). Rolot and Seutin (1999) increased phosphorus 
concentration to $160 \mathrm{mg} / \mathrm{L}$ in nutrient solution to induce tuberization in potato plants. Results showed that more phosphorus had a positive effect on multiplication rate and increased tuber numbers from 6.4 (in peat culture) to 6.96 per plant. Rosen \& Bierman (2008) reported that phosphorus fertilizer application increased total number of tubers per plant.

\section{CONCLUSIONS}

Fine composition of growth media significantly reduced petiole phosphorus concentration; however did not affect leaf nitrogen percent. Reduced foliar P concentration was demonstrated by low biological yield and reduced multiplication rate of potato micropropagated plantlets. Results showed that coarse composition (30\% of $0-3 \mathrm{~mm}$ and $70 \%$ of $3-6 \mathrm{~mm}$ ) of growth media was the best composition for potato minituber production in hydroponic sand culture.

\section{REFERENCES}

AOAC. (1984): Official methods of analysis. Association on official analytical chemists, 14th ed., Washington DC, USA.

Balemi, T. (2009): Effect of phosphorus nutrition on growth of potato genotypes with contrasting phosphorus efficiency. African Crop Science Journal., 17(4): 199-212.

Caron, J. \& Nkongolo, N. V. (2004): Assessing gas diffusion coefficients in growing media from in situ water flow and storage measurements. Vadose Zone Journal., 3: $300-311$.

Cary, J. W. (1986): Effects of relative humidity, oxygen and carbon dioxide on initiation and early development of stolons and tubers. American Potato Journal., 63: 619628.

Cherif, M. Tirilly, Y. \& Belanger, R. R. (1997): Effect of oxygen concentration on plant growth, lipid peroxidation and receptivity of tomato roots to pythium $\mathrm{F}$ under hydroponic conditions. European Journal Plant Pathology., 103: 255-264.

Cho, M. S. Park, Y. Y. Jun, H. J. \& Chung, J. B. (2006): Growth of Gerbera in mixtures of coir dust and perlite. Horticulture Environment and Biotechnology., 47: 211216.

Dole, J. M. \& Wilkins, H. F, (1999): Floriculture principles and species. Prentice-Hall, Inc. USA. pp. 79-89.

Farran, I. \& Mingo-Castel, A. M. (2006): Potato mini-tuber production using aeroponics: effect of plant density and harvesting intervals. American Journal Potato Research., 83: 47-53.

Jenkins, P. D. Ali, H. (1999): Growth of potato cultivars in response to application of phosphate fertilizer. Annal Applied Biology., 135: 431-438.

Jenkins, P. D. \& Ali, H. (2000): Phosphate supply and progeny tuber numbers in potato crops. Annal Applied biology., 136: 41-46.

Kleinkopf, G. E. Westermann, D. T. Wille, M. J. \& Kleinscmidt G. D. (1987): Specific gravity of Russet Burbank potatoes. American Journal Potato Research., 64: 597587.

Minocha, R. Shortle, W. C. Long, S. L. \& Minocha, S. C. (1994): A rapid and reliable procedure for extraction of cellular polyamines and inorganic ions from plant tissues. Journal of Plant Growth Regulation., 13: 187-193. 
Murashige, T. \& Skoog, F. (1962): A revised medium for rapid growth and bioassays with tobacco tissue cultures. Physiologia Plantarum., 15: 473-497.

Novella, M. B. Andriolo, J. L. Bisognin, D. A. Cogo, C. M. \& Bandinelli, M. G. (2008): Concentration of nutrient solution in the hydroponic production of potato minitubers. Ciênc Rural., 38: 1529-1533.

Pursglove, J. D. \& Sanders, F. E. (1981): The growth and phosphorus economy of the early potato (Solanum tuberosum). Communications in Soil Science and Plant Analysis., 12: 1105-1121.

Rolot, J. L. Seutin, H. (1999): Soilless production of potato mini-tubers using a hydroponic technique. Potato Research., 42: 457-469.

Rosen, C. J. \& Bierman, P. M. (2008): Potato Yield and Tuber Set as Affected by Phosphorus Fertilization. American Journal Potato Research., 85: 110-120.

Terry, N. \& Ulrich, A. (1973): Effects of P deficiency on the photosynthesis and respiration of leaves in sugar beet. Plant Physiology., 51: 43-47.

Thorup, R. M. (1984): The role of phosphorus in plant growth. In: R. M. Thorup (ed.) Agronomy Handbook: A Practical Guide to Soil Fertility and Fertilizer Use. Chevron Chemical Co. San Francisco CA. pp. 57-80.

Watson, D. J. \& Wilson, J. H. (1956): An analysis of the effects of infection with leaf-roll virus on the growth and yield of potato plants, and of its interactions with nutrient supply and shading. Annal Applied Biology., 44: 390-409.

Wever, G. Baas, R. Marques, J. C. \& Van Aanholt, L. J. (2001): Gas concentration measurement in horticultural growing media. Acta Horticulture., 554: 149-156.

Vreugdenhil, D. Struik, P. C. (1989): An integrated view of the hormonal regulation of tuber formation in potato (Solanum tuberosum). Physiologia Plantarum., 75: 525531.

Westermann, D. T. \& Kleinkopf, G. E. (1985): Phosphorus relationships in potato plants. Agronomy Journal., 77: 490-494. 